\title{
Structural features and relaxation properties of PET/PC blends containing impact strength modifier and chain extender
}

\author{
S. S. Pesetskii ${ }^{*}$, O. V. Filimonov ${ }^{2}$, V. N. Koval ${ }^{1}$, V. V. Golubovich ${ }^{1}$ \\ ${ }^{1}$ Department of Technology of Polymeric Composite Materials and Particles, V.A. Belyi Metal-Polymer Research Insti- \\ tute of National Academy of Sciences of Belarus, 32a, Kirov Street, 246050 Gomel, Republic of Belarus \\ ${ }^{2}$ MFK ‘Chemical Corporation', 29, Lazarenko St., Mogilev 212009, Republic of Belarus
}

Received 19 April 2009; accepted in revised form 1 July 2009

\begin{abstract}
It has been investigated how methylene diphenyl diisocyanate (MDI) influences the morphology, rheological, mechanical and relaxation properties, as well as PET crystallizability, of PET/PC/(PP/EPDM) ternary blends produced by the reactive extrusion process. It appears that irrespective of phase structure of the blends, MDI causes a rise in melt viscosity (decreased MFI-values) of the material which is the result of an increased molecular weight of the macromolecules; PET crystallization becomes retarded. MDI improves compatibility between PET and PC in PET/PC/(PP/EPDM) ternary blends. Addition of MDI leads to higher values of the dynamic shear modulus for PET high elastic state (in the temperature range between $T_{g}$ PET and cool crystallization temperature of PET); the PET cool crystallization and melt crystallization processes become retarded; the PET and PC glass transition temperatures approach one another. MDI has been shown not to influence significantly the blend morphology or the character of interaction between the PP/EPDM disperse phase and PET/PC blend matrix.
\end{abstract}

Keywords: polymer blends, poly(ethylene terephthalate), polycarbonate, impact modifier, chain extender

\section{Introduction}

The blends of polycarbonate (PC) with poly(alkylene terephthalates), particularly poly(ethylene terephthalate) (PET), have been the subject of much attention from researchers as well as scientific schools [1-4]. This can mainly be explained by growing possibilities for developing PET/PC-based engineering materials; their properties are far more advantageous than those of the two homopolymers. Besides, when making blends, it seems possible to use - at least as one of the blend components industrial or/and household wastes, for example, used (post-consumer) PET bottles. As a result, the commercial production of similar materials becomes quite profitable.
One of the disadvantages of PET/PC binary blends is their low impact strength measured on notched samples [2]. PET/PC blend materials show relatively high values of impact strength only at temperatures between the component glass transition temperatures ( $T_{g}$ PET and $T_{g}$ PC) [2]. For practical applications, therefore, such PET/PC blends are most suitable that contain special additives, i.e. impact strength modifiers (ISM) [5] which can increase the impact strength.

Another important problem that arises during compounding and processing of PET/PC molten blends is to prevent hydrolytic and thermal degradation of macromolecules of polyesters being blended. This problem comes, first of all, from the fact that 
molten blends are usually processed at a temperature of $270^{\circ} \mathrm{C}$ or higher, because PET has a high melting temperature; the reaction rate turns out to be high and causes degradation of the macromolecular chains [6]. The reactions of macromolecular breakdown lead to reduced molecular weights, lower values of mechanical properties and lower thermal stability, which unfavorably influences the possibility of repeated processing or recycling of polyester materials [7].

Complete polycondensation initiated in the solid phase is one of the ways to prevent a negative influence of macromolecular breakdown on the properties of polycondensation thermoplastics, among them saturated polyesters such as PET and PC $[8,9]$. High technological expenses required for the solid-state additional polycondensation, however, make reprocessing of polyester raw materials unprofitable.

During the last $10-15$ years especially, alternative technologies have been developed for the modification of polyesters. These technologies show essential advantages compared with the solid-state polycondensation. These alternative technologies are mostly based on chemical transformations of macromolecules in molten polyesters; such chemical transformations occur with the help of additional bi- or multi-functional chemicals capable of extending the chain (so-called chain extenders) [10-15]. The chain extenders (CE) interact in melt mostly with terminal functional groups of polyester macromolecules and link them with one another; so the molecular weight does decrease, it rather increases to some extent. It was established that reactions of interaction between macromolecules and CE proceed most favourably in melt in the reactor-extruder equipped with one or two screws [16-18]. Usually, a vacuum treatment and special catalysts are used to promote these reactions [18]. This technology based on extrusion equipment becomes economically advantageous for processing polyester materials. Its abilities have been mainly investigated only for certain types of polyesters. It hasn't been understood clearly what role is played by $\mathrm{CE}$ in polyester blends of a more complex composition. An example of such blends is PET/PC containing ISM. The purpose of this work is to consider structural details and relaxation properties of these blends.

\section{Experimental}

\subsection{Materials}

The material was PET produced commercially by Mogilevhimvolokno Co. (Grade PET-8200 intended for making bottles and other types of packages; intrinsic viscosity, $0.882 \mathrm{dl} / \mathrm{g}$; concentration of terminal carboxyl groups, $22.8 \mathrm{mmole} / \mathrm{kg}$; glass transition temperature, $T_{g}$ PET $=80^{\circ} \mathrm{C}$ ). The second basic component for the blend was PC produced by Zarya Co, Russia (molecular weight $\approx 35000$; $T_{g}$ PC $\left.=144.5^{\circ} \mathrm{C}\right)$. The ISM was elastomer PP/ EPDM based on a mixture of polypropylene and ethylene-propylene-diene rubber (melting temperature of the polypropylene component $T_{m} \mathrm{PP}=$ $165.5^{\circ} \mathrm{C}$; crystallization temperature $T_{c r} \mathrm{PP}=$ $110.5^{\circ} \mathrm{C} ; \mathrm{MFI}=2.8 \mathrm{~g} / 10 \mathrm{~min}\left(\right.$ at $T=210^{\circ} \mathrm{C} ; P=$ $21.6 \mathrm{~N} ; D_{c}=2.095 \mathrm{~mm}$ ); high flow limit of strain $10 \mathrm{MPa}$; relative elongation at rupture $595 \%$; glass transition temperature $T_{g}=-40^{\circ} \mathrm{C}$ ). The PP/EPDM concentration was constant, $5 \mathrm{wt} \%$, in all of the compositions tested (Table 1). The chain extender, as in work [19], was methylene diphenyl diisocyanate (MDI); its concentration was $1 \mathrm{wt} \%$.

Table 1. Compositions of test materials

\begin{tabular}{|c|l|}
\hline $\begin{array}{c}\text { Compo- } \\
\text { sition } \\
\text { No }\end{array}$ & \multicolumn{1}{|c|}{$\begin{array}{c}\text { Components and their concentration } \\
\text { [wt } \%]\end{array}$} \\
\hline 1 & $\mathrm{PET}-100 \mathrm{wt} \%$ \\
\hline 2 & $\mathrm{PC}-100 \mathrm{wt} \%$ \\
\hline 3 & $\mathrm{PET} / \mathrm{PC}-25 \mathrm{wt} \% /(\mathrm{PP} / \mathrm{EPDM})-5 \mathrm{wt} \%$ \\
\hline 4 & $\mathrm{PET} / \mathrm{PC}-50 \mathrm{wt} \% /(\mathrm{PP} / \mathrm{EPDM})-5 \mathrm{wt} \%$ \\
\hline 5 & $\mathrm{PET} / \mathrm{PC}-75 \mathrm{wt} \% /(\mathrm{PP} / \mathrm{EPDM})-5 \mathrm{wt} \%$ \\
\hline 6 & $\mathrm{PET} / \mathrm{PC}-25 \mathrm{wt} \% /(\mathrm{PP} / \mathrm{EPDM})-5 \mathrm{wt} \% / \mathrm{MDI}-1 \mathrm{wt} \%$ \\
\hline 7 & $\mathrm{PEt} / \mathrm{PC}-50 \mathrm{wt} \% /(\mathrm{PP} / \mathrm{EPDM})-5 \mathrm{wt} \% / \mathrm{MDI}-1 \mathrm{wt} \%$ \\
\hline 8 & $\mathrm{PET} / \mathrm{PC}-75 \mathrm{wt} \% /(\mathrm{PP} / \mathrm{EPDM})-5 \mathrm{wt} \% / \mathrm{MDI}-1 \mathrm{wt} \%$ \\
\hline
\end{tabular}

\subsection{Preparation of blend compositions and test samples}

The blend compositions have been compounded by the reactive extrusion method on extrusion-granulating line based on the twin-screw extruder TSK35/40 (China); the screws diameters were $35 \mathrm{~mm}$ each; $L / D=40$. The melt temperature in the extrusion zone was $265^{\circ} \mathrm{C}$. MDI was introduced into the blend material as follows. First PET and PC granules were dried. Then the mixture of these granules was treated by MDI immediately before loading it into the material cylinder of the extruder. 
The test samples for measuring values of the mechanical properties of the materials were injection moulded on machine EN-30 (Taiwan); screw diameter, $35 \mathrm{~mm}$; shot volume, $30 \mathrm{~cm}^{3}$. The mould temperature was set equal to $50^{\circ} \mathrm{C}$.

The relaxation spectrometry was performed on plates of dimensions: $50 \times 5 \times 1 \mathrm{~mm}$. The plates were made on laboratory-type moulding plunger machine with a shot volume of $2.5 \mathrm{~cm}^{3}$.

Before compounding and making test samples the materials have been dried to a residual moisture content below $0.02 \%$.

\subsection{Methods of analysis}

The mechanical properties of the materials in tension were determined on a universal testing machine Instron 5657 (Great Britain). The Charpy impact viscosity was determined on Charphy notched samples using the pendulum hammer PSW-1.5 (Germany). The test samples were blades with a neck measuring $50 \times 5 \times 3 \mathrm{~mm}$ and bars: $80 \times 10 \times 4 \mathrm{~mm}$. The rheological properties were judged by MFI-values found at $T=265^{\circ} \mathrm{C}, P=$ $21.6 \mathrm{~N}$ and $D_{c}=2.095 \mathrm{~mm}$ (instrument IIRT-AM, Russia).

The analysis of temperature dependences of mechanical loss tangent $(\tan \delta)$ and dynamic shear modulus $\left(G^{\prime}\right)$ of the samples gave information on the dynamic-mechanical (relaxation) properties of the materials. The tests were run as in other works $[2,20]$, using the reverse torsion pendulum of design developed at MPRI NAS, Belarus. The test frequency was $1 \mathrm{~Hz}$. The measurement accuracy was: $0.1{ }^{\circ} \mathrm{C}$ for temperature; $\pm 3 \%$ for $\tan \delta ; \pm 1 \%$ for $G^{\prime}$. The test samples - plates measuring
$50 \times 5 \times 1 \mathrm{~mm}-$ were injection moulded on the laboratory moulding machine of plunger type; the shot volume was $5 \mathrm{~cm}^{3}$.

The structural morphology of the materials was studied by SEM-images taken of sections of bars (from the central portion of bars) after they had been exposed to liquid nitrogen for $30 \mathrm{~min}$. The scanning electron microscope was VEGA II LSH (Czech Republic). The differential scanning analysis was performed using an instrument DSM-10M (Russia) at a heating/cooling rate of $16^{\circ} \mathrm{C} / \mathrm{min}$ with weighed samples of $8 \mathrm{mg}$ each. The samples were used for the analysis taken from the middle part of the specimens used for the relaxation spectrometry.

\section{Results and discussion}

\subsection{Effect of MDI on mechanical and rheological properties of PET/PC/(PP/EPDM)}

It can be seen in Table 2 that MDI $-1 \mathrm{wt} \%$ added to $\mathrm{PET} / \mathrm{PC} /(\mathrm{PP} / \mathrm{EPDM})$ blends regardless of their phase structure changes their properties. It is worth mentioning that in PET/PC blends containing PC$25 \%$ the dispersed medium was formed by PET whereas with PC-50\% there were two continuous media - PET and PC. With PC-75\%, the dispersed phase was PET [21]. The blends modified by MDI showed a somewhat higher level of mechanical properties such as $\sigma_{L F}, \sigma_{H F}, \varepsilon_{r}$ and $a$ (Table 2). An addition of MDI distinctly increased $K_{s}$. The MFIvalues were noticed to decrease for all of the compositions. The latter fact is indicative of efficiency of MDI as a chain extender in the blends under investigation [19]. It can be understood, therefore, that PP/EPDM present in PET/PC blends is not

Table 2. Values of mechanical and rheological properties of materials

\begin{tabular}{|c|c|c|c|c|c|c|}
\hline $\begin{array}{c}\text { Composition } \\
\text { No }\end{array}$ & $\begin{array}{c}\text { MFI } \\
{[\mathrm{g} / 10 \mathrm{~min}]}\end{array}$ & $\begin{array}{c}\sigma_{\mathrm{HF}} \\
{[\mathrm{MPa}]}\end{array}$ & $\begin{array}{c}\sigma_{\mathrm{LF}} \\
{[\mathrm{MPa}]}\end{array}$ & $\begin{array}{c}\mathbf{K}_{\mathbf{s}} \\
{[\%]}\end{array}$ & $\begin{array}{c}\varepsilon_{\mathrm{r}} \\
{[\%]}\end{array}$ & $\begin{array}{c}\mathbf{a} \\
{\left[\mathbf{k J} / \mathbf{m}^{2}\right]}\end{array}$ \\
\hline 1 & 23.0 & 55 & 30 & 100 & 232 & 7.4 \\
\hline 2 & 6.1 & 68 & 53 & 98 & 126 & 16.6 \\
\hline 3 & 22.0 & 53 & 34 & 87 & 180 & 17.7 \\
\hline 4 & 17.0 & 55 & 38 & 84 & 140 & 19.6 \\
\hline 5 & 13.0 & 56 & 42 & 86 & 146 & 48.3 \\
\hline 6 & 18.0 & 54 & 35 & 95 & 214 & 19.0 \\
\hline 7 & 14.0 & 56 & 39 & 94 & 142 & 21.4 \\
\hline 8 & 11.0 & 54 & 43 & 90 & 150 & 49.5 \\
\hline
\end{tabular}

Here and henceforth, the compositions are marked as in Table $1 . \sigma_{H F}, \sigma_{L F}, \varepsilon_{\mathrm{r}}$ are, respectively, high and low flow limits and relative elongation at rupture; $K_{s}$ is strength factor for melt weld flow in injection moulding determined from the expression: $\sigma_{H F 1} / \sigma_{H F 2} \cdot 100 \%$, where $\sigma_{H F 1}$ and $\sigma_{H F 2}$ - are, respectively, values of the upper flow limit for blade-samples moulded by melt injection in the face plane of one end and of two ends; $a$ is Charpy impact strength measured on sharply notched samples at $T=23^{\circ} \mathrm{C}$. 
harmful towards MDI used as a chain extender for polyester materials. However, despite a decrease in MFI (a higher melt viscosity), the blends modified by MDI showed an increase in $K_{s}$. As this factor much depends on both the melt viscosity and on adhesion strength interaction between the phases in blends of thermodynamically incompatible or partly compatible polymers, it can be assumed that incorporated MDI causes an intensification of interphase adhesion in PET/PC blends along with an enhancement in compatibility of the components.

Table 2 shows that Charpy impact strength values determined for notched samples of compositions No.5 and No.8 are much higher than for compositions No.3-4 and 6-7. An obvious reason for this is the fact that in compositions No.3-4 and 6-7, the non-impact-resistant PET forms a continuous (disperse) medium. In compositions No.5 and No. 8 the disperse medium is PC, whose impact strength much exceeds a-values for PET (Table 2, compositions No.1 and No.2). Thus the reason for a sharp rise in $a$ values for compositions No.5 and No.8 is
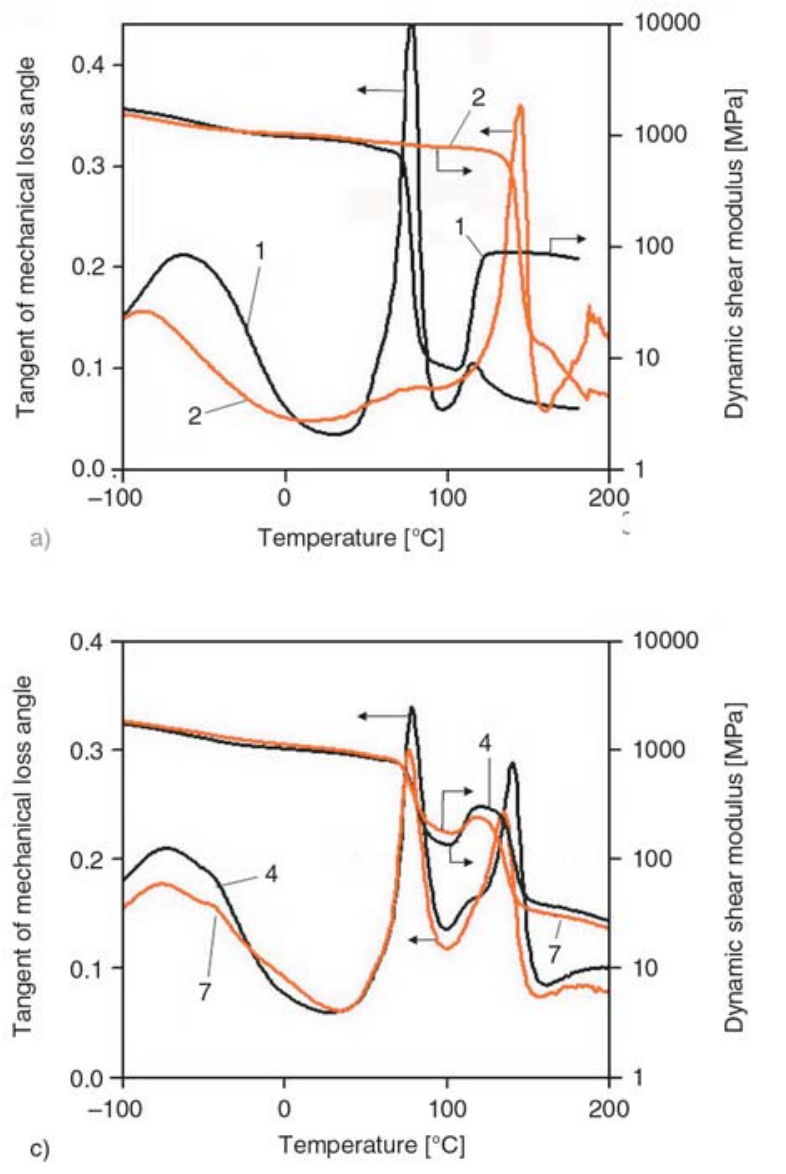

Figure 1. Mechanical loss tangent and dynamic shear modulus for polyester materials: here and henceforth the numbers of compositions are designated by digits on curves in accordance with Table 1

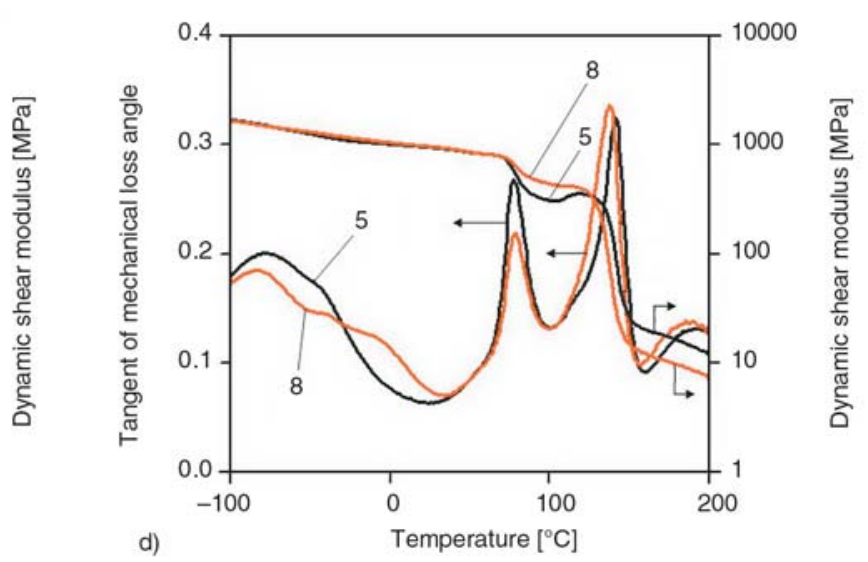

that the impact strength level for them is supported mainly by PC phase; PC is highly resistant to impact breakdown that follows chiefly the mechanism of shear flow [2]. In the blends studied, the effect of PP/EPDM is evidently reduced to increasing the degree of heterogeneity of the blend in general and of PC phase in particular. MDI acting as a chain extender encouraged an increase is shear flow resistance of the material at impact loading. That is why all of the compositions containing MDI show somewhat higher $a$-values.

\subsection{Dynamic-mechanical properties of the blends}

Relaxation spectrometry allows estimating variations in dynamic mechanical properties of blends within a wide temperature range and yields experimental data which can be indicative of specific interactions between phases in blends [2, 20,21]. The temperature dependences of $\tan \delta$ and $G^{\prime}$ for initial PET and PC, as well as blend compositions based on them, are shown in Figure 1. Numerical

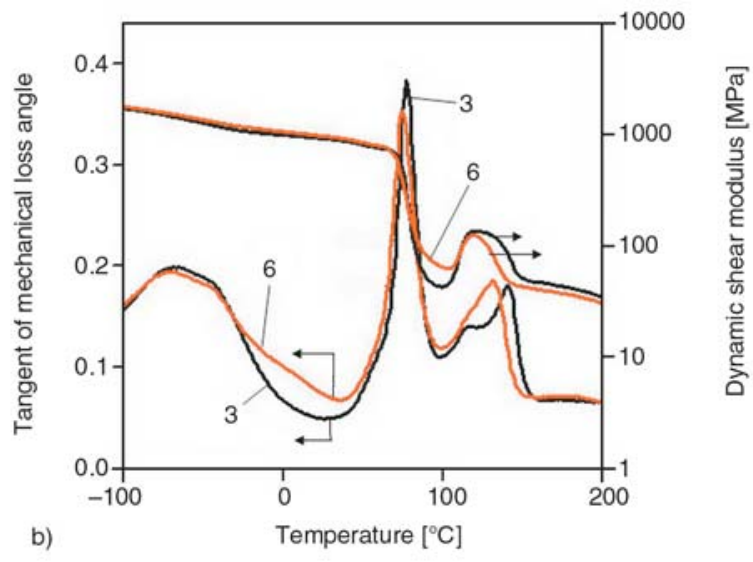


Table 3. Values of parameters characterizing relaxation properties of polyester materials

\begin{tabular}{|c|c|c|c|c|c|c|}
\hline $\begin{array}{c}\text { Composition } \\
\text { No }\end{array}$ & $\begin{array}{c}\mathbf{T}_{\mathbf{g} \text { PET }} \\
{\left[{ }^{\circ} \mathbf{C}\right]}\end{array}$ & $\begin{array}{c}\mathbf{T}_{\mathbf{g}} \mathbf{P C} \\
{\left[{ }^{\circ} \mathbf{C}\right]}\end{array}$ & $\begin{array}{c}\Delta \mathbf{T}_{\mathbf{g}} \\
{\left[{ }^{\circ} \mathbf{C}\right]}\end{array}$ & $\begin{array}{c}\mathbf{T}_{\boldsymbol{\beta}} \\
{\left[{ }^{\circ} \mathbf{C}\right]}\end{array}$ & $\begin{array}{c}\mathbf{G}^{\prime}{ }_{\mathbf{1 0 0}} \\
{[\mathbf{M P a}]}\end{array}$ & $\begin{array}{c}\Delta \mathbf{G}^{\prime}{ }_{\mathbf{c c}} \\
{[\mathbf{M P a}]}\end{array}$ \\
\hline 1 & 76.5 & - & - & -61.3 & 8 & 82 \\
\hline 2 & - & 144.5 & - & -87.3 & 795 & - \\
\hline 3 & 76.8 & 141.0 & 64.2 & -66.8 & 43 & 93 \\
\hline 4 & 78.0 & 141.2 & 63.2 & -71.7 & 136 & 166 \\
\hline 5 & 77.6 & 141.6 & 64.0 & -76.9 & 308 & 84 \\
\hline 6 & 74.3 & 132.0 & 57.7 & -70.4 & 65 & 60 \\
\hline 7 & 78.0 & 135.0 & 57.0 & -74.2 & 158 & 59 \\
\hline 8 & 78.2 & 138.0 & 59.8 & -82.3 & 437 & 0 \\
\hline
\end{tabular}

$\Delta T_{g}=T_{g} \mathrm{PC}-T_{g} \mathrm{PET} ; T_{\beta}$ is temperature of main maximum within the $\beta$-relaxation temperature region; $G_{100}^{\prime}$ is dynamic shear modulus at $100^{\circ} \mathrm{C} ; \Delta G_{c c}^{\prime}$ is a rise in $G^{\prime}$ values with respect to $G_{100}^{\prime}$ caused by cool crystallization of PET

values of the parameters that characterize relaxation properties of the materials are listed in Table 3. An analysis of the available information led to several important conclusions about the effect of MDI on relaxation behaviour and interphase interactions in $\mathrm{PET} / \mathrm{PC} /(\mathrm{PP} / \mathrm{EPDM})$ ternary blends.

It can be understood from Table 3 that after MDI was added the values of $T_{g}$ for PET and PC approach one another. The value of $\Delta T_{g}$ decreases mainly at the expense of decreased $T_{g}$ PC, not at the expense of increased $T_{g}$ PET. This can be explained by an improved compatibility of the components under the effect of MDI, as well as by plastification of PC by the amorphous phase of PET the $T_{g}$ values of which are lower than $T_{g}$ PC. The addition of MDI makes the values of major peak of $\beta$-relaxation shift appreciably, by $3.5-5.4^{\circ} \mathrm{C}$, to the lower temperature region. The kinks present in the peak maximum of $\beta$-relaxation at $T=-41^{\circ} \mathrm{C}$ are a result of simultaneous glass transition process of PP/EPDM elastomeric phase and $\beta$-relaxation process of basic components of blend (PET and PK). $T_{g}$ of pure $\mathrm{PP} / \mathrm{EPDM}$ is $-40^{\circ} \mathrm{C}$. The scanning spectroscopy data show that not only at the segmental level, but also at the level of PET and PC monomer units, effective intermolecular interactions take place; MDI plays an essential role in them.

After MDI was added, $T_{\beta}$ values of the blends shifted (by $\approx 5.4^{\circ} \mathrm{C}$ ) to the lower temperature region. The lower $T_{\beta}$ values predetermine an opportunity of developing more frost-resistant (lower brittle temperature) materials based on MDI-modified blends.

The most important consequence of MDI added to the PET/PC/(PP/EPDM) ternary system is a con- siderable rise in dynamic shear modulus values within the region of high elastic state of PET (at temperatures between $T_{g}$ PET and cool crystallization of PET in blend, being $\approx 120^{\circ} \mathrm{C}$ as determined by the scanning spectroscopy technique). For a quantitative estimation of this effect, Table 3 gives $\Delta G_{100}^{\prime}$ values which approximately correspond to $G^{\prime}$ minimum values of the materials when PET in blends undergoes devitrification.

After PET was devitrified and the blend was heated to $\approx 120^{\circ} \mathrm{C}$, the amorphous portion of this polymer undergoes cool crystallization, and $G^{\prime}$ values of the material rise (Figure 1, Table 3). The presence of MDI in the blend material causes PET cool crystallization to proceed at a slower rate up to complete stopping in PET/PC $-75 \% /(\mathrm{PP} / \mathrm{EPDM})-5 \% /$ MDI $-1 \%$ blends (for these blends $\Delta G_{c c}^{\prime}=0$, Table 3). It can be seen that a rise in $\Delta G_{100}^{\prime}$ has been caused by a more active interphase (segmental) interaction between the amorphous PC and amorphous phase of the devitrified PET. It is owing to stronger adhesion between the phases - and, probably, to partial mutual dissolution of the components that restricts segmental mobility - that PET cool crystallization is either retarded or suppressed in blends containing MDI. Some earlier works had described the determinative effect of segmental mobility on crystallizability of partly crystalline thermoplastics [21-23].

\subsection{Results obtained by differential scanning calorimetry technique}

It was established earlier that mechanical properties of PET-based blend materials much depend on the tendency of this polymer to crystallize. An increase 
Table 4. DSC-results obtained for polyester materials

\begin{tabular}{|c|c|c|c|c|c|c|c|}
\hline \multirow{2}{*}{$\begin{array}{c}\text { Composition } \\
\text { No }\end{array}$} & \multicolumn{2}{|c|}{ Cool crystallization at heating } & \multicolumn{2}{|c|}{ Melting } & \multicolumn{2}{|c|}{ Crystallization at melt cooling } & \multirow{2}{*}{$\mathbf{a}^{\mathrm{a}}[\%]$} \\
\hline & $\mathbf{T}_{\mathbf{c ~ c r}}\left[{ }^{\circ} \mathbf{C}\right]$ & $\Delta \mathbf{H}_{\mathrm{c} \mathrm{cr}}[\mathrm{J} / \mathrm{g}]$ & $\mathbf{T}_{\mathrm{m}}\left[{ }^{\circ} \mathbf{C}\right]$ & $\Delta \mathbf{H}_{\mathrm{m}}[\mathrm{J} / \mathrm{g}]$ & $\mathbf{T}_{\mathrm{cr}}\left[{ }^{\circ} \mathbf{C}\right]$ & $\Delta \mathbf{H}_{\text {cr }}[\mathrm{J} / \mathrm{g}]$ & \\
\hline 1 & 130.4 & 28.2 & 253.3 & 44.1 & 194.4 & 27.7 & 11.0 \\
\hline 3 & 139.5 & 15.5 & 251.0 & 25.2 & 177.8 & 25.9 & 9.5 \\
\hline 4 & 143.6 & 13.1 & 252.8 & 18.8 & 182.3 & 25.8 & 8.2 \\
\hline 5 & 139.0 & 7.4 & 249.5 & 9.2 & 179.9 & 8.6 & 5.5 \\
\hline 6 & 145.3 & 12.0 & 244.0 & 21.1 & 165.5 & 29.3 & 8.9 \\
\hline 7 & 146.6 & 10.8 & 248.9 & 13.4 & 169.0 & 14.5 & 3.9 \\
\hline 8 & 148.0 & 4.5 & 252.5 & 5.7 & 160.7 & 8.5 & 3.4 \\
\hline
\end{tabular}

aCrystallinity $a=\left(\Delta H_{m}-\Delta H_{c c r}\right) \cdot 100 /\left(k \cdot \Delta H_{m}^{*}\right)$, where $\Delta H_{m}$ is latent melting heat, $\Delta H_{c c r}$ is latent heat of cool crystallization,

$\Delta H_{m}^{*}=144.664 \mathrm{~J} / \mathrm{g}$ is latent melting heat of PET with $100 \%$-crystallinity [19], $k$ is PET concentration (in wt parts) in the material

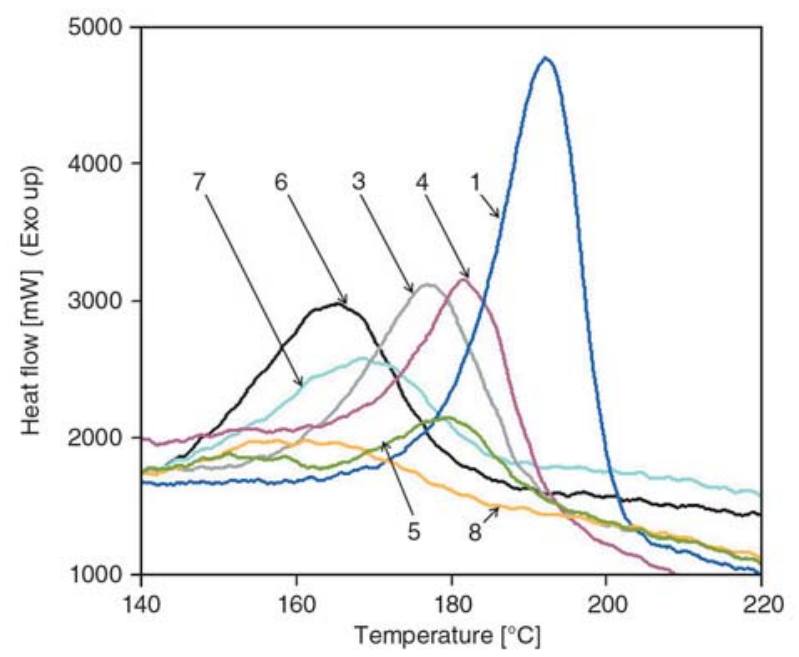

Figure 2. DSC-curves for cooling polyester blends

in the rate of crystallization and in crystallinity of the PET-component can result in a decrease in the blends plasticity and impact strength [24].

The results of analysis of PET crystallizability for tested blend materials are compared with initial polyester in Figure 2 and Table 4. The most important result of DSC-analysis is that the presence of MDI leads to rate retardation of crystallization and a lower crystallinity in a blend. The severity of MDI influence upon PET crystallizability was found to depend on the blend composition: the higher the PC concentration in the blend, the stronger the influence of MDI. This can be explained by the fact that in $\mathrm{PET} / \mathrm{PC} /(\mathrm{PP} / \mathrm{EPDM})$ ternary blends, PET undergoes crystallization at a slower rate, in comparison with pure polyester, because of interaction with PC-component [2].

The influence of MDI on PET crystallization in melt is especially easily visualized when analyzing DSC-curves of cooling. It can be seen in Figure 2 and Table 4 that in comparison with pure PET and a binary blend, the extent of melt overcooling reaches $20^{\circ} \mathrm{C}$ in order to ensure PET crystallization.
Thus in MDI - modified blends, diisocyanate acts as a chain extender and increases the PET molecular weight. It also interacts with terminal groups of PET and PC macromolecules, and obviously is helpful in forming copolymers. As a result the PET molecular mobility is restricted causing PET crystallization to proceed at a slower rate. The introduction of MDI in a PET/PC/(PP/EPDM) system may be one of the effective ways to make PET amorphous in the material.

Cuts of blends were made in liquid nitrogen and SEM-images (Figure 3) were analyzed to reveal that all of the blends morphologically look identical. Within a PET/PC quasi-homogeneous matrix, PP/EPDM forms sphere-like particles of a maximum size between some fractions of a micrometer up to 3 to $4 \mu \mathrm{m}$. Larger particles are relatively few. In these micrographs it is impossible to distinguish and identify phases of the composites independently of the phase structure of the materials because the interaction between PET and PC is intensive and they partly compatible in the blends investigated. No traces of a foreign phase are present on PP/EPDM particles which implies that there are no strong specific interactions between the impact strength modifier used and PET/PC blend matrix irrespective of the type and phase structure of the blends. It appears, therefore, that MDI modifies predominantly the basic components of the PET/ PC blend matrix and not PP/EPDM and its interaction with the polyester matrix.

\section{Conclusions}

The reactive blending of PET, PC, $5 \mathrm{wt} \%$ of impact strength modifier - PP/EPDM - and MDI - 1wt $\%$ has been observed to cause great variations in the molecular structure and values of main properties 

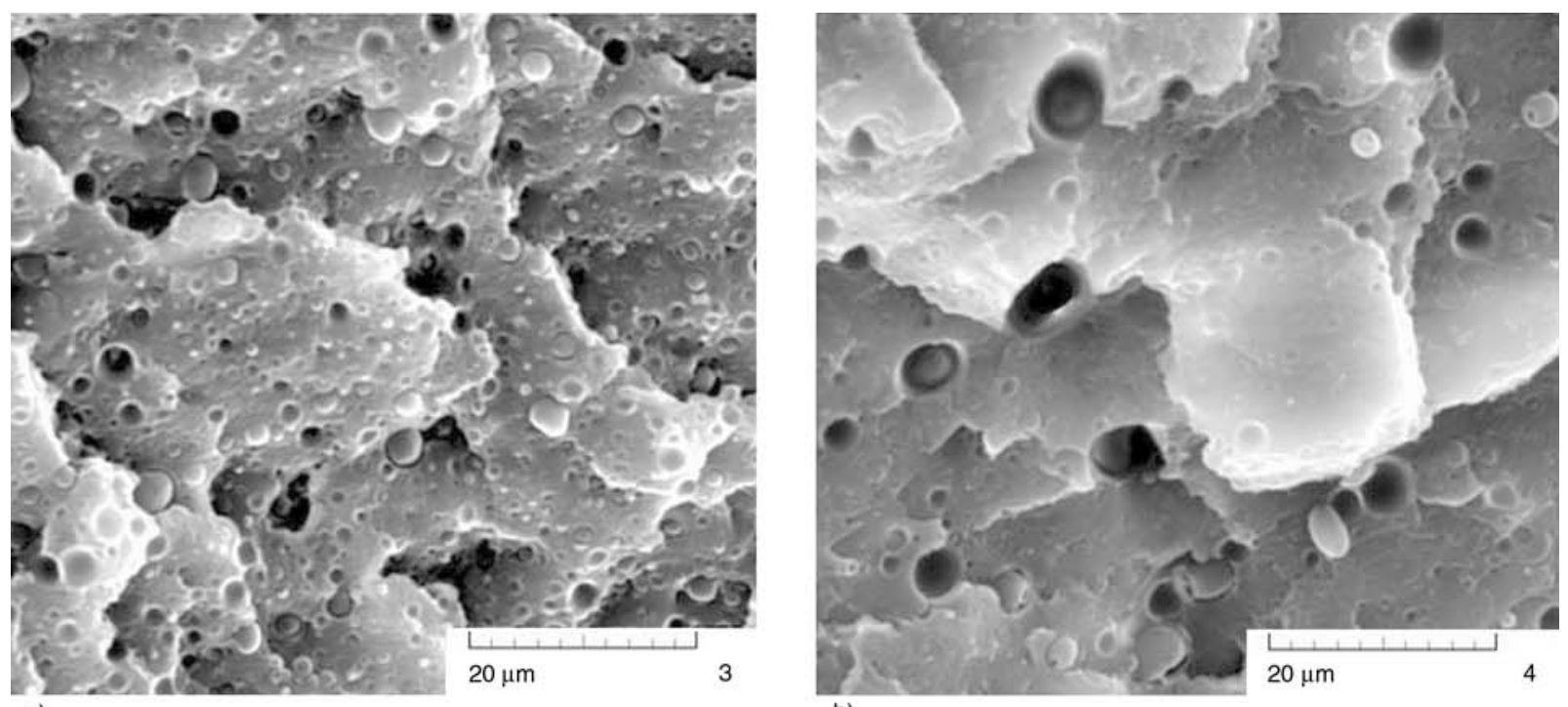

a)
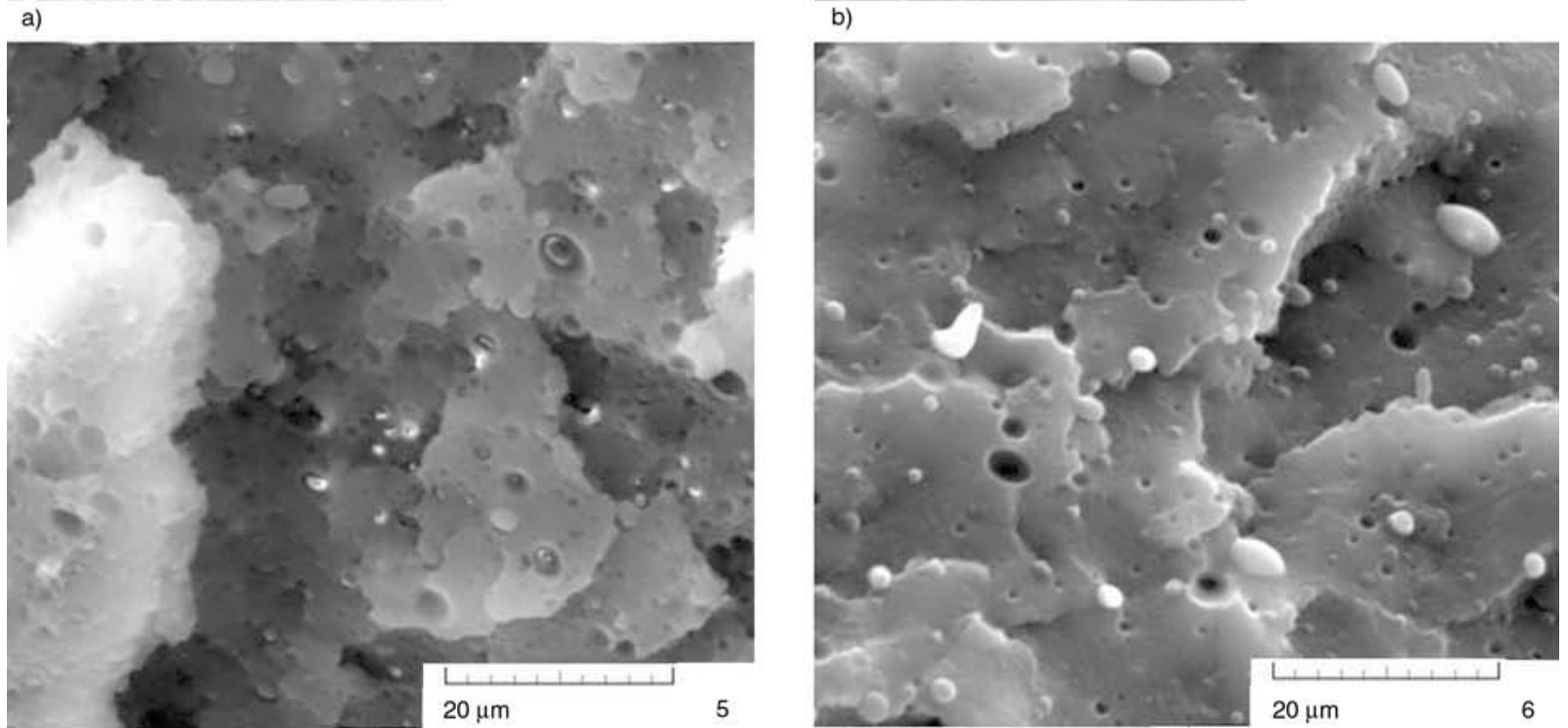

c)

d)

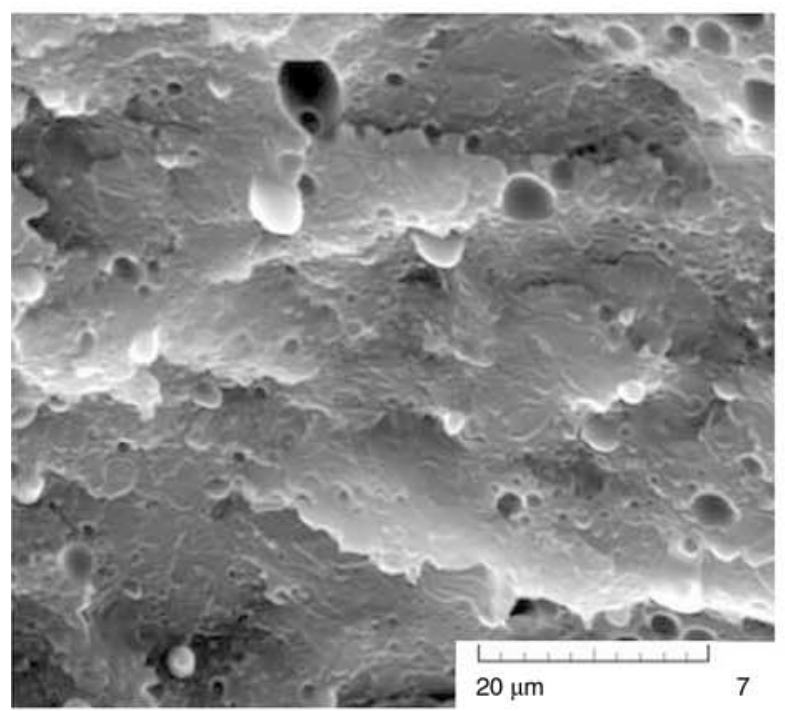

e)

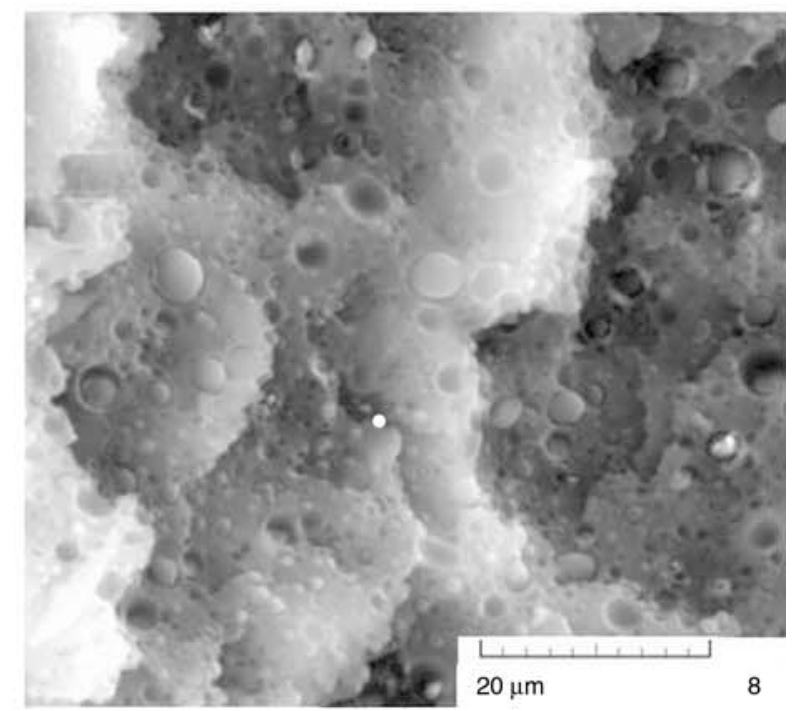

f)

Figure 3. SEM-images (a-f) of polyester blend sections (3-8) cut under liquid nitrogen 
of the materials under discussion. The addition of MDI leads to increased melt viscosity of the material (decreased MFI values) which can be explained by increased molecular weights of the components; PET crystallization proceeds at a lower rate. MDI improves compatibility of PET and PC in PET/PC/ (PP/EPDM) ternary blends. This modifier causes a substantial rise in the dynamic shear modulus within the region of PET high elastic state (over the temperature range between $T_{g}$ PET and temperature of PET cool crystallization). It also promotes approach of PET and PC glass transition temperatures; the processes of PET cool crystallization and crystallization from melt become retarded. MDI does not cause a noticeable influence on the blend morphology and on the character of interaction between the PP/EPDM disperse phase and PET/PC blend matrix.

\section{References}

[1] Samious C. K., Kalfoglou N. K.: Compatibility characterization of polycarbonate/copolyester blends. Polymer, 41, 5759-5767 (2000). DOI: $10.1016 / \mathrm{S} 0032-3861(99) 00803-4$

[2] Pesetskii S. S., Jurkowski B., Koval V. N.: Polycarbonate/polyalkylene terephthalate blends: Interphase interactions and impact strength. Journal of Applied Polymer Science, 84, 1277-1285 (2002).

DOI: $10.1002 / a p p .10472$

[3] Lee S-S., Jeong H. M., Jho J. Y., Ahn T. O.: Miscibility of poly(ethylene terephthalate)/poly(estercarbonate) blend. Polymer, 41, 1773-1782 (2000). DOI: $10.1016 / \mathrm{S} 0032-3861(99) 00328-6$

[4] Kong Y., Hay J. N.: Miscibility and crystallization behavior of poly(ethylene terephthalate)/polycarbonate blends. Polymer, 43, 1805-1811 (2002). DOI: $10.1016 / \mathrm{S} 0032-3861(01) 00772-8$

[5] Pesetskii S. S., Koval V. N., Starzhynsky V. E.: Method for making impact resistant composition. Russian Patent 2028335, Russia (1995).

[6] Zimmerman H., Kim N. T.: Investigation on thermal and hydrolytic degradation of poly(ethylene terephthalate). Polymer Engineering and Science, 20, 680683 (1980).

DOI: $10.1002 /$ pen.760201008

[7] Karger-Kocsis J.: Recycling options for post-consumer PET and PET-containing wastes by melt blending. in 'Handbook of Thermoplastic Polyesters' (ed.: Fakirov S.) Wiley-VCH, Weinheim, Vol 2, 12911318 (2002).
[8] Shima T., Urasaki T., Oka I.: Improved process for polycondensation of high-molecular-weigh poly(ethylene terephthalate) in the presence of acid derivatives. Advances in Chemistry, 128, 183-207 (1973).

[9] Buxbaum L. H.: Solid-state polycondensation of poly(butylene terephthalate). Journal of Applied Polymer Science: Applied Polymer Symposium, 35, 59-66 (1979).

[10] Inata H., Matsumura S.: Chain extenders for polyesters. I. Addition-type chain extenders reactive with carboxyl and groups of polyesters. Journal of Applied Polymer Science, 30, 3325-3337 (1985). DOI: $10.1002 /$ app.1985.070300815

[11] Inata H., Matsumura S.: Chain extenders for polyesters. II. Reactivities of carboxyl-addition type chain extenders: Bis cyclic-imino-ethers. Journal of Applied Polymer Science, 32, 5193-5202 (1986). DOI: 10.1002/app.1986.070320534

[12] Inata H., Matsumura S.: Chain extenders for polyesters. III. Addition-type nitrogen-containing chain extenders reactive with hydroxyl end croups of polyesters. Journal of Applied Polymer Science, 32, 45814594 (1986). DOI: $10.1002 / \mathrm{app} .1986 .070320423$

[13] Inata H., Matsumura S.: Chain extenders for polyesters. IV. Properties of the polyesters chain-extended by 2.2'-bis (2-oxasoline). Journal of Applied Polymer Science, 33, 3069-3079 (1987). DOI: $10.1002 / a p p .1987 .070330838$

[14] Japon S., Boogh L., Leterrier Y., Mànson J-A. E.: Reactive processing of poly(ethylene terephthalate) modified with multifunctional epoxy-based additives. Polymer, 41, 5809-5818 (2000). DOI: $\underline{10.1016 / \mathrm{S} 0032-3861(99) 00768-5}$

[15] Villalobos M., Awojulu A., Greeley T., Turco G., Deeter G.: Oligomeric chain extenders for economic reprocessing and recycling of condensation plastics. Energy, 31, 3227-3234 (2006). DOI: 10.1016/j.energy.2006.03.026

[16] Bikiaris D. N., Karayannidis G. P.: Thermomechanical analysis of chain extended PET and PBT. Journal of Applied Polymer Science, 60, 55-61 (1996). DOI: 10.1002/(SICI)1097-4628(19960404)60:1<55:: AID-APP7>3.0.CO;2-U

[17] Bikiaris D. N., Karayannidis G. P.: Chain extension of polyesters PET and PBT with $N, N^{\prime}$-bis(glycidylester)pyromillitimides. I. Journal of Polymer Science Part A: Polymer Chemistry, 33, 1705-1714 (1995). DOI: $10.1002 /$ pola.1995.080331017

[18] Inata H., Matsumura S.: Chain extenders for polyesters. V. Reactivities of hydroxyl-addition-type chain extender 2,2'-bis(4h-3,1-benzoxazin-4-one). Journal of Applied Polymer Science, 34, 2609-2617 (1987). DOI: $10.1002 / a p p .1987 .070340724$ 
[19] Tang X., Guo W., Yin G., Li B., Wu C.: Reactive extrusion of recycled poly(ethylene terephthalate) with polycarbonate by addition of chain extender. Journal of Applied Polymer Science, 104, 2602-2607 (2007).

DOI: 10.1002/app.24410

[20] Pesetskii S. S., Jurkowski B., Storozhuk I. P., Koval V. N.: Blends of polycarbonate and polysulphonepolydimethyl-siloxane block copolymers: Analysis of compatibility and impact strength. Journal of Applied Polymer Science, 73, 1823-1834 (1999).

DOI: $10.1002 /($ SICI $) 1097-4628(19990906) 73: 10$ $\leq 1823:$ :AID-APP1>3.0.CO;2-7

[21] Pol D., Newman S.: Polymer blends. Academic Press, New York (1978).
[22] Pesetskii S. S., Jurkowski B., Olkhov Yu. A., Bogdanovich S. P., Koval V. N.: Influence of cooling rate on structure of PA 6. European Polymer Journal, 41, 1380-1390 (2005).

DOI: $10.1016 /$ j.eurpolymj.2004.12.009

[23] Pesetskii S. S., Bogdanovich S. P., Koval V. N.: Structural features and stability of amorpholous phase in polyamide 6 blocks. Materials, Technologies, Instruments, 11, 29-34 (2006).

[24] Yu Z-Z., Yang M-S., Dai S-C., Mai Y-W.: Toughening of recycled poly(ethylene terephthalate) with a maleic anhydride grafted SEBS triblock copolymer. Journal of Applied Polymer Science, 93, 1462-1472 (2004).

DOI: 10.1002/app.20592 